\title{
Primary central sleep apnea and anesthesia: a retrospective case series
}

\section{Apnées centrales du sommeil primaires et anesthésie: une série de cas rétrospective}

\author{
Alexandru Alexa, MD · Meghna P. Mansukhani, MD • Bhargavi Gali, MD • \\ Atousa Deljou, MD $\cdot$ Juraj Sprung, MD, PhD $\cdot$ Toby N. Weingarten, MD
}

Received: 2 January 2018/Revised: 8 March 2018/Accepted: 9 March 2018/Published online: 1 May 2018

(c) Canadian Anesthesiologists' Society 2018

\begin{abstract}
Purpose Primary (idiopathic) central sleep apnea (PCSA) is a rare central sleep-related breathing disorder characterized by increased chemoreceptor sensitivity to partial pressure of carbon dioxide, which manifests as hyperventilation followed by apnea during non-rapid eye movement sleep. The purpose of this retrospective study was to describe the postoperative course of patients who had PCSA and underwent procedures requiring anesthetic management.
\end{abstract}

Methods Patients who received a diagnosis of PCSA at our institution and required procedural anesthesia between 1 January 2010 and 1 June 2016 underwent a comprehensive review of their health records with a focus on identifying respiratory complications.

Results Ten patients (nine males, one female) underwent 47 procedures requiring anesthetic management: 20 (43\%) under general anesthesia, 25 (53\%) with monitored anesthetic care, and two (4\%) with regional anesthesia. Procedures were complicated by second-degree heart block in one patient and pneumonia in another two (one had Ivor-Lewis esophagectomy and the other bronchoscopy to evaluate worsening lung infiltration). Hypoxemia (oxyhemoglobin saturation $<90 \%$ for three minutes) developed in three patients during anesthesia recovery. One was possibly due to PCSA-a 73-yr-old

A. Alexa, MD · B. Gali, MD - A. Deljou, MD · J. Sprung, MD, $\mathrm{PhD} \cdot \mathrm{T}$. N. Weingarten, MD $(\bowtie)$

Department of Anesthesiology and Perioperative Medicine, Mayo Clinic, 200 First St SW, Rochester, MN 55905, USA e-mail: weingarten.toby@mayo.edu

M. P. Mansukhani, MD

Center for Sleep Medicine, Mayo Clinic, Rochester, MN, USA male with alcoholic cirrhosis who was moderately sedated and hypoxemic after orthopedic surgery; his oxygenation improved with an adaptive servoventilator positive airway pressure device and supplemental oxygen. His underlying medical condition or level of sedation may have contributed to hypoxemia. The other patients became hypoxemic after bronchoscopy. No other cases were complicated by postoperative respiratory compromise.

Conclusions No major adverse outcomes were related to PCSA postoperatively. Nevertheless, continuation of home positive airway pressure therapy during anesthesia recovery was useful in one patient who had cirrhosis and postoperative hypoxemia.

\section{Résumé}

Objectif Les apnées centrales du sommeil primaires (idiopathiques) (ACSP) constituent une pathologie centrale rare de la respiration liée au sommeil; elle est caractérisée par une augmentation de la sensibilité des chimiorécepteurs à la pression partielle de dioxyde de carbone qui se manifeste par une hyperventilation suivie d'une apnée au cours des périodes de sommeil sans mouvements oculaires rapides. L'objectif de cette étude rétrospective était de décrire l'évolution postopératoire des patients ayant des ACSP et qui avaient subi des procédures nécessitant une anesthésie.

Méthodes Les dossiers médicaux de patients ayant reçu un diagnostic d'ACSP dans notre établissement et nécessitant une procédure sous anesthésie entre le $1^{\text {er }}$ janvier 2010 et le $1^{\text {er }}$ juin 2016 ont été complètement réexaminés à la recherche, notamment, de complications respiratoires.

Résultats Dix patients (9 hommes, 1 femme) ont subi 47 procédures nécessitant une gestion anesthésique : 20 
(43\%) sous anesthésie générale, 25 (53\%) sous sédation et deux (4\%) sous anesthésie régionale. Les procédures ont été compliquées par un bloc de branche du deuxième degré et deux cas de pneumonie (un patient avait subi une osophagectomie d'Ivor-Lewis et l'autre une bronchoscopie pour évaluer l'aggravation d'un infiltrat pulmonaire). Une hypoxémie (saturation en oxyhémoglobine $<90 \%$ pendant au moins trois minutes) est apparue chez trois patients durant la période de fin d'anesthésie. Dans un cas, elle était possiblement liée à l'ACSP chez un homme de 73 ans présentant une cirrhose éthylique qui avait reçu une sédation modérée et était hypoxémique après une chirurgie orthopédique. Son oxygénation s'est améliorée avec l'utilisation d'un dispositif à pression positive, un servoventilateur adaptatif et un supplément d'oxygène. Son état médical sous-jacent ou son niveau de sédation peut avoir contribué à l'hypoxémie. Les autres patients sont devenus hypoxémiques après une bronchoscopie. Aucun autre cas n'a présenté de complication respiratoire postopératoire.

Conclusions Aucun effet indésirable majeur n'a été lié à l'ACSP en période postopératoire. Néanmoins, la poursuite de la thérapie par pression positive habituelle au domicile pendant la période de sortie de l'anesthésie a été utile chez un patient atteint de cirrhose et présentant une hypoxémie postopératoire.

Primary central sleep apnea (PCSA) is a rare form of idiopathic central sleep apnea (CSA) occurring without an identifiable cause such as congestive heart failure, environmental factors (e.g., high altitude), or pharmacologic causes (e.g., opioids). ${ }^{1}$ Patients with PCSA have increased chemosensitivity to partial pressure of carbon dioxide $\left(\mathrm{PaCO}_{2}\right)$, and they hyperventilate while awake or asleep. ${ }^{2}$ During sleep, patients have episodic periods of hyperventilation, which decreases $\mathrm{PaCO}_{2}$ below the apneic threshold and thereby triggers central sleepdisordered breathing events such as apnea. ${ }^{3}$ In contrast to obstructive sleep apnea (OSA) where respiratory efforts are maintained, CSA is characterized by a reduction or cessation of airflow (i.e., lack of breathing) with absent or diminished respiratory efforts (Figure). ${ }^{4}$

Automatic or adaptive servoventilator (ASV) positive airway pressure devices can eliminate apnea and normalize ventilatory patterns by adjusting pressure support. ${ }^{5,6}$ Standard positive pressure devices and pharmacologic therapies can paradoxically worsen the condition. ${ }^{5-7}$

Patients with OSA have an increased risk of postoperative respiratory complications after surgical procedures. $^{8,9}$ In those patients, opioids and other sedatives can worsen upper airway obstruction and hypoventilation and suppress arousal responses after apneic episodes. ${ }^{10}$ Nevertheless, limited information is available on the postoperative outcomes for patients with CSA syndromes. ${ }^{11}$

Opioid-induced CSA is one type of central sleep-related breathing disorder, ${ }^{11}$ but it is not known whether short-term postoperative use of opioid analgesics is detrimental in patients with other types of CSA syndromes. Because patients with PCSA have hypersensitivity to $\mathrm{PaCO}_{2}$ and opioids depress the central respiratory drive and responsiveness to $\mathrm{PaCO}_{2}{ }^{12}$ these patients could have unpredictable responses to drugs during anesthesia. As PCSA is a rare disorder, there are no published reports on the perioperative outcomes in this unique group of patients.

Accordingly, with this study we sought to retrospectively review the records of patients with PCSA who underwent procedures requiring anesthesia care at a large tertiary medical centre and characterize their postoperative course with particular attention to evidence of postoperative respiratory compromise.

\section{Methods}

This study was approved by the Mayo Clinic Institutional Review Board (no. 16-004188; approved 6 June 2016) and included only patients who had provided authorization for research use of their medical records (consistent with Minnesota Statute 144.295); thus, further consent for review of medical records for this study was waived by the Institutional Review Board. This study conformed to the requirements of the Strengthening the Reporting of Observational Studies in Epidemiology (STROBE) statement.

Study design and patient selection

This retrospective study assessed perioperative outcomes among patients with known PCSA undergoing procedures that required anesthetic management at a major academic tertiary medical centre. These patients were a subset of a study designed to evaluate the effects of ASV treatment of CSA syndromes on healthcare utilization (Mayo Clinic Institutional Review Board no. 16-001896; approved 12 April 2016). Patients were identified from the Rochester Epidemiology Project database if they had received a diagnosis of CSA (International Classification of Diseases, Ninth Revision codes 327.2, 327.20, 327.21, 327.22, 327.24, 327.25, 327.26, 327.27, and 327.29) on overnight polysomnography (Current Procedural Terminology codes 95800, 95801, 95806, 95807, 95808, 95810, 95811, 95782, and 95783) in Olmsted County, Minnesota, and if they 
Figure Polysomnographic Studies of Sleep Apnea Patterns. A) This 60-sec polysomnographic fragment shows evidence of obstructive sleep apnea (in red). There is an absence of airflow (thick arrows) with continued partial chest and abdominal respiratory effort throughout the events with thoracoabdominal paradox noted (thin arrows). B) This 60 sec polysomnographic fragment shows evidence of central sleep apnea (in green). There is absence of airflow (thick arrows) with no chest and abdominal respiratory effort (thin arrows). Abdominal = abdominal inductance plethysmography; Airflow = oronasal thermistor and nasal pressure transducer recordings; ECG = electrocardiogram; EEG = electroencephalogram; EMG $=$ electromyogram; $\mathrm{EOG}=$ electro-oculogram; $\mathrm{SpO}_{2}=$ oxyhemoglobin saturation; Sum $=$ summation channel of thoracic and abdominal effort channels; Thoracic $=$ thoracic inductance plethysmography
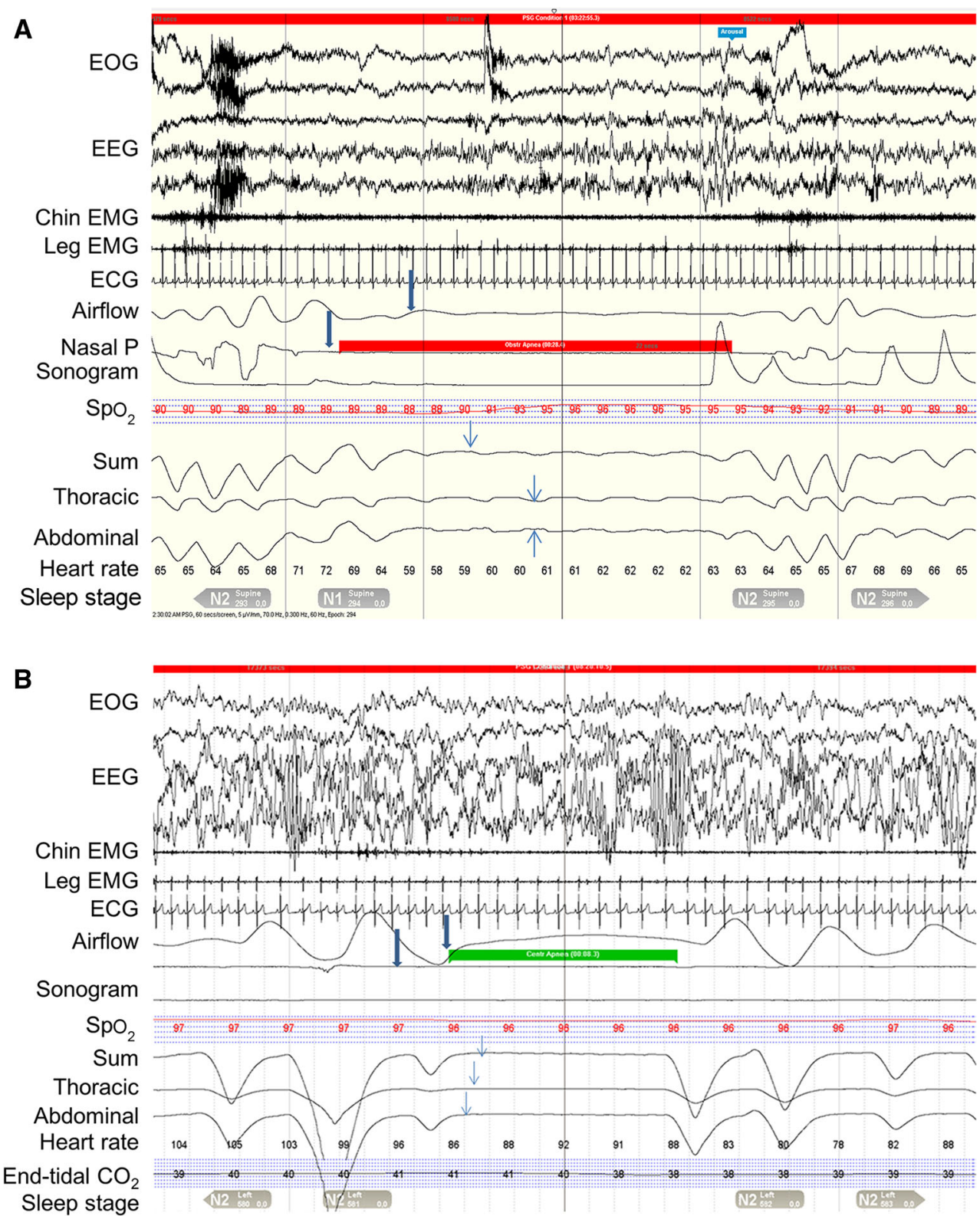

were using prescribed ASV therapy at home at settings that were effective for CSA on polysomnography. ${ }^{13,14}$

All patients had a comprehensive consultation with a sleep medicine specialist at our centre preceding an inlaboratory polysomnography investigation. All patients had a manual review of their medical records and sleep evaluation, including clinical notes, medications, polysomnographic findings, and laboratory and other test results to confirm eligibility and assign the CSA syndrome subtype. Severity of CSA was determined by the apneahypopnea index as mild $\left(<15\right.$ events. $\left.\mathrm{hr}^{-1}\right)$, moderate, ${ }^{15-29}$ or severe $(\geq 30){ }^{1}$ Patients were designated as having PCSA if no known cause was found for CSA at the time of diagnosis after comprehensive review of the medical record by a sleep medicine clinician (M.P.M.). The records of patients with PCSA were reviewed to identify those who underwent procedures requiring perioperative management between 1 January 2010 and 1 June 2016. This time frame was selected to reflect contemporary anesthetic practice and therapy for PCSA.

\section{Data abstraction}

The medical records of identified patients were reviewed for sleep centre evaluation, overnight polysomnography, treatments related to PCSA (pharmacologic and noninvasive ventilatory management therapies), and underlying comorbidities. Surgical records were reviewed for types of surgical procedures, anesthetic techniques, medications administered, and notable intraoperative 
complications. Post-anesthesia records were reviewed for complications recorded during anesthesia recovery in the postanesthesia care unit (PACU) as well as signs of oversedation (assessed with the Richmond Agitation-Sedation Scale $[\mathrm{RASS}])^{15}$ and respiratory compromise. ${ }^{16,17}$ Respiratory compromise was defined as episodes of hypoventilation (three episodes of $<8$ respirations $\cdot \min ^{-1}$ ) apnea (episode of apnea $\geq$ ten seconds), hypoxemia (three episodes of oxyhemoglobin desaturation as measured by pulse oximetry $[<90 \%$ with or without nasal cannula]), or pain/sedation mismatch (defined as RASS of -3 to -5 and a numeric pain score $>5$ on a scale from 0 [no pain] to 10 [worst pain imaginable]). ${ }^{16,17}$ All patients at our institution admitted to the PACU are continuously monitored for these signs of respiratory compromise. ${ }^{16,17}$ As per institutional protocols, patients who have repeated episodes of respiratory compromise are monitored via telemetry. Postoperative records were reviewed for complications, unexpected readmissions, and death that occurred during the hospitalization or within 30 days of surgery. Data were summarized using descriptive statistics.

\section{Results}

We identified 318 patients with CSA who were using prescribed ASV therapy at home, of which 16 had received a diagnosis of PCSA. During the study time frame, ten of the patients identified with PCSA underwent a procedure requiring anesthetic management. Patient characteristics at the sleep evaluation are summarized in Table 1. All patients had received a diagnosis of moderate $(n=3$; $30 \%)$ or severe $(n=7 ; 70 \%)$ PCSA. None had periodic or ataxic breathing patterns on polysomnography, and none had been prescribed pharmacologic agents for treatment of PCSA. These patients underwent a total of 47 procedures: $20(43 \%)$ required general anesthesia, 25 (53\%) with monitored anesthetic care and two (4\%) with a regional nerve block (Table 2). Non-depolarizing neuromuscular blockade was used in 11 procedures (23\%) and was reversed with neostigmine in nine. No major intraoperative complications occurred; however, in a 58-yr-old male undergoing Ivor-Lewis esophagectomy for esophageal adenocarcinoma, atrial fibrillation with rapid ventricular response developed during one lung ventilation and then converted to normal sinus rhythm with diltiazem.

In 42 of the procedures, the patients were admitted to the PACU for anesthesia recovery and were routinely given supplemental oxygen. In the other five procedures, patients bypassed the PACU-after two minor procedures, the patients were discharged directly to the outpatient area after they received monitored anesthesia care; after two late-night operations, the patients underwent anesthesia recovery in the operating room and were then discharged to the postsurgical ward. The patient who underwent IvorLewis esophagectomy remained tracheally intubated and was discharged directly to the intensive care unit. During anesthesia recovery in the PACU, Mobitz type II, a seconddegree heart block, developed in a patient who subsequently received a pacemaker, and three episodes of hypoxemia developed in two patients. One of these two was a 73-yr-old male with alcoholic cirrhosis that developed several years after PCSA had been diagnosed; he underwent open repair of a femoral fracture, had moderate sedation in the PACU (RASS score, -3), and had repeated episodes of hypoxemia, which resolved with application of his ASV device in combination with supplemental oxygen. The other patient was an 80 -yr-old female with granulomatous lung disease; hypoxemia developed after two bronchoscopic evaluations for worsening pulmonary infiltrates and recurrent pneumonia. There was no other documentation of respiratory compromise episodes (e.g., apnea) in the PACU.

After 14 of the 47 procedures $(30 \%)$, the patients were admitted postoperatively; after 33 procedures $(70 \%)$, the patients were discharged home on the day of the procedure. Patients scheduled for admission following the procedure were instructed to bring their home positive airway pressure (PAP) device to the hospital for postoperative use. After eight of the $14(57 \%)$ admissions, patients were monitored postoperatively with continuous pulse oximetry; after 6 of the admissions (43\%), patients were administered opioid analgesics (after four of those admissions, patients were monitored with continuous pulse oximetry); after one of the admissions (7\%), the patient was administered zolpidem (continuation of home medication) and was monitored with continuous pulse oximetry. On postoperative day 9 , the 58-yr-old male who underwent esophagectomy required endotracheal reintubation and mechanical ventilation for hypoxemic respiratory failure attributed to aspiration pneumonia. Two patients were readmitted after hospital discharge: the 80-yr-old female with recurrent pneumonia who underwent bronchoscopy the day after discharge and a 40-yr-old male who underwent cystoscopy six days after discharge for unrelated eye pain and dizziness. There were no postoperative deaths within the first 30 days.

\section{Discussion}

The main finding from this cohort of PCSA patients using home ASV who underwent procedures requiring anesthesia is that, with one possible exception, there were no postoperative adverse anesthetic outcomes related to 
Table 1 Characteristics of patients with primary central sleep apnea undergoing anesthesia

\begin{tabular}{|c|c|c|c|c|c|c|c|c|c|}
\hline \multirow[t]{2}{*}{$\begin{array}{l}\text { Age, } \\
\text { yr/sex }\end{array}$} & \multicolumn{4}{|c|}{$\begin{array}{l}\text { Baseline sleep study } \\
\text { findings }\end{array}$} & \multirow[t]{2}{*}{$\begin{array}{l}\text { Mean } \\
\mathrm{SpO}_{2}\end{array}$} & \multirow[t]{2}{*}{$\begin{array}{l}\text { Minimum } \\
\mathrm{SpO}_{2}\end{array}$} & \multirow[t]{2}{*}{ Relevant medications } & \multirow[t]{2}{*}{$\begin{array}{l}\text { ASV device settings } \\
\text { for EPAP, } \mathrm{cmH}_{2} \mathrm{O}\end{array}$} & \multirow[t]{2}{*}{ Major comorbidities } \\
\hline & $\mathrm{AHI}$ & b CAI & OMAI & $\mathrm{HI}$ & & & & & \\
\hline $83 / \mathrm{M}$ & 37 & 27 & 0 & 9 & 92 & 73 & Trazodone & $7^{\mathrm{c}}$ & Mild cognitive impairment \\
\hline $70 / \mathrm{M}$ & 65 & 36 & 11 & 18 & 92 & 86 & None & $8^{c}$ & Alcoholic liver disease \\
\hline $76 / \mathrm{M}$ & 83 & 80 & 0 & 3 & 92 & 83 & None & $6^{\mathrm{c}}$ & HTN, DM \\
\hline $65 / \mathrm{M}$ & 53 & 24 & 4 & 25 & 93 & 81 & None & $8^{c}$ & HTN \\
\hline $80 / \mathrm{M}$ & 69 & 48 & 14 & 6 & 92 & 81 & None & $6^{\mathrm{c}}$ & HTN, DM, Hx of TIA \\
\hline $75 / \mathrm{M}$ & 94 & 79 & 4 & 10 & 94 & 83 & $\begin{array}{l}\text { Zolpidem, modafinil, } \\
\text { pramipexole, lorazepam } \\
\text { (anxiety) }\end{array}$ & $11^{\mathrm{c}}$ & $\begin{array}{l}\text { AFib (absent at diagnosis of CSA), } \\
\text { HTN, Hx of TIA }\end{array}$ \\
\hline $58 / \mathrm{M}$ & 95 & 70 & 19 & 5 & 92 & 75 & None & $5^{\mathrm{c}}$ & $\begin{array}{l}\text { Esophageal adenocarcinoma, CAD, } \\
\text { HTN, DM }\end{array}$ \\
\hline $71 / \mathrm{M}$ & 19 & 8 & 7 & 2 & 94 & 85 & None & $6^{\mathrm{c}}$ & $\begin{array}{l}\text { CAD, AFib (absent at CSA } \\
\text { diagnosis), AAA repair, HTN, } \\
\text { DVT, DM }\end{array}$ \\
\hline $80 / \mathrm{F}$ & 21 & 8 & 9 & 4 & 92 & 84 & Trazodone, pramipexole & $7^{\mathrm{c}}$ & $\begin{array}{l}\text { Hx of stroke, HTN, granulomatous } \\
\text { lung disease }\end{array}$ \\
\hline $40 / \mathrm{M}$ & 23 & 22 & 0 & 1 & 92 & 83 & Clonazepam (sleep, anxiety) & $7^{\mathrm{d}}$ & $\begin{array}{l}\text { HTN, SVT post ablation, lower } \\
\text { limb spasticity of undetermined } \\
\text { cause }\end{array}$ \\
\hline
\end{tabular}

$\mathrm{AAA}=$ abdominal aortic aneurysm; AFib = paroxysmal atrial fibrillation; AHI = apnea-hypopnea index (events per hour); ASV $=$ automatic or adaptive servoventilator; $\mathrm{CAD}=$ coronary artery disease; $\mathrm{CAI}=$ central apnea index (events per hour); $\mathrm{CSA}=$ central sleep apnea; $\mathrm{DM}=$ diabetes mellitus; DVT = deep vein thrombosis; EPAP = expiratory positive airway pressure $\left(\mathrm{cmH}_{2} \mathrm{O}\right)$; HTN = arterial hypertension; Hx = history; $\mathrm{HI}=$ hypopnea index (events per hour); OMAI = obstructive and/or mixed apnea index (events per hour); PS max = maximum pressure support $\left(\mathrm{cmH}_{2} \mathrm{O}\right) ;$ PS min = minimum pressure support $\left(\mathrm{cmH}_{2} \mathrm{O}\right) ; \mathrm{SpO}_{2}=$ oxyhemoglobin saturation $(\%) ; \mathrm{SVT}=$ supraventricular tachycardia; TIA = transient ischemic attack

a Age at diagnosis of primary central sleep apnea

b AHI: 5-14, mild; 15-29, moderate; $\geq 30$, severe central sleep apnea

c Adaptive servoventilator device (ResMed) with default settings of PS min, $3 \mathrm{cmH}_{2} \mathrm{O}$; PS max, $15 \mathrm{~cm} \mathrm{H}_{2} \mathrm{O}$; backup rate of auto

d Automatic servoventilator device (Philips Respironics) with settings of PS min, $3 \mathrm{cmH}_{2} \mathrm{O}$; PS max, $12 \mathrm{~cm} \mathrm{H}_{2} \mathrm{O}$; backup rate of auto

PCSA. The possible exception was a 72-yr-old male who underwent a femoral fracture repair and had postoperative hypoxemia related to moderate sedation. After PCSA was initially diagnosed in this patient, he received a diagnosis of alcoholic cirrhosis, which could have contributed to the deterioration in oxygenation status. ${ }^{18}$ Additionally, we previously observed that over-sedation and respiratory depression are common during anesthesia recovery after lower extremity orthopedic procedures ${ }^{19}$; thus, it is difficult to attribute this patient's postoperative hypoxemia to PCSA. His level of sedation and hypoxemia did improve with ASV therapy and supplemental oxygen. Unfortunately, an arterial blood gas sample was not obtained during this event. The other post-procedural pulmonary complications could have been attributed to the procedures themselves (i.e., the bronchoscopies and esophagectomy). It is important to note that after eight of the 14 postoperative hospital admissions, patients had continuous monitoring of their oxygen saturation with continuous pulse oximetry.

Even though the pathophysiology of CSA and OSA overlaps considerably, making the distinction difficult, PCSA differs in several important ways from OSA. CSA is considered to be the primary diagnosis when central disordered breathing events occur at least five times per hour during sleep and these events comprise more than $50 \%$ of the total disordered breathing events on polysomnography. ${ }^{1,20}$ In patients with PCSA, these central sleep-disordered breathing events typically occur during non-rapid eye movement sleep and occur in isolation or in clusters during the sleep cycle. ${ }^{7}$ Patients with PCSA have increased chemosensitivity to $\mathrm{PaCO}_{2}$; thus, they tend to hyperventilate long term with resultant hypocarbia. $^{2}$ During non-rapid eye movement sleep, patients have cyclic episodes of hyperventilation that decrease the $\mathrm{PaCO}_{2}$ to a level below the apneic 
Table 2 Anesthetic outcomes of 47 procedures

\begin{tabular}{|c|c|}
\hline Surgical/anesthetic characteristics and complications & Value \\
\hline \multicolumn{2}{|l|}{ Type of surgery, no. (\%) } \\
\hline General & $5(10.6)$ \\
\hline Orthopedic & $7(14.9)$ \\
\hline Ophthalmologic & $8(17.0)$ \\
\hline Cardiac & $1(2.1)$ \\
\hline Urologic & $13(27.7)$ \\
\hline Miscellaneous & $13(27.7)$ \\
\hline Duration, median (range), min & $72(42-123)$ \\
\hline \multicolumn{2}{|l|}{ Type of anesthesia, no. (\%) } \\
\hline General & $20(42.6)$ \\
\hline Monitored anesthesia care & $25(53.2)$ \\
\hline Regional & $2(4.3)$ \\
\hline Perioperative benzodiazepine $^{a}$ & $10(21.3)$ \\
\hline Opioid IV morphine equivalents, median (range) ${ }^{\mathrm{b}}$ & $9.5(2.5-21.8)$ \\
\hline NDMD/reversed, no./no. & $11 / 9$ \\
\hline \multicolumn{2}{|l|}{ Intraoperative events, no. (\%) } \\
\hline SVT/Afib with RVR & $1(2.1)$ \\
\hline \multicolumn{2}{|l|}{ Recovery room events $(n=42)$} \\
\hline Duration, median (range), min & $63(37.5-90.5)$ \\
\hline Duration $>2 \mathrm{~h}$, no. $(\%)$ & $5(11.9)$ \\
\hline RASS $\leq-2$, no. $(\%)$ & $5(11.9)$ \\
\hline Hypoxemia, no. (\%) & $3(7.1)$ \\
\hline \multicolumn{2}{|l|}{ Unanticipated complications, no. (\%) } \\
\hline Second-degree heart block, Mobitz type 2 & $1(2.1)$ \\
\hline Intensive care unit admission (hypoxemic respiratory failure) & $1(2.1)$ \\
\hline Admission due to hypoxemia, no. (\%) & $2(4.3)$ \\
\hline Readmission $<30$ days after procedure, no. (\%) & $2(4.3)$ \\
\hline
\end{tabular}

threshold, resulting in cessation or reduction of central respiratory effort. Sleep is disrupted and patients may be fatigued during the day. PCSA, unlike other CSA syndromes, lacks an underlying cause, such as congestive heart failure or chronic opioid use.

Because PCSA is rare, little has been published on pharmacologic therapeutic options to improve symptoms and correct respiratory abnormalities ${ }^{6}$ (Table 3). Acetazolamide counteracts the chronic respiratory alkalosis in patients with PCSA. In two small nonrandomized trials, acetazolamide decreased the central apnea and central hypopnea indices and decreased daytime sleepiness. $^{23,27}$ In a small nonrandomized trial with zolpidem $^{22}$ and a small, randomized cross-over trial with triazolam, ${ }^{21}$ these medications decreased the central apnea indices and attenuated PCSA symptoms. Nevertheless, concerns that these medications could worsen respiratory depression and hypoxemia (e.g., from other underlying sleep disorders such as OSA or a concomitant pulmonary condition) have resulted in recommendations that they be used as second-line agents only and in patients under close clinical observation. ${ }^{6,22}$ In this cohort, zolpidem was used in only one patient, and this patient used it long term. There is no evidence regarding de novo use of pharmacologic sleep aids in such patients, and the use of these aids in the postoperative period should be done cautiously.

The use of opioids, which depress the respiratory drive to $\mathrm{PaCO}_{2}$, has not been described for patients with PCSA. Indeed, CSA due to long-term opioid therapy is itself one of the five recognized CSA syndromes, and increased daily 
Table 3 Therapy for primary central sleep apnea

\begin{tabular}{|c|c|c|}
\hline Therapy & Mechanism & Application in clinical practice \\
\hline \multicolumn{3}{|l|}{ Pharmacologic therapy } \\
\hline $\begin{array}{l}\text { Respiratory } \\
\text { stimulants }^{7,20}\end{array}$ & Increases central drive to breathe & $\begin{array}{l}\text { There is no recommendation for respiratory stimulants as } \\
\text { therapy for PCSA in the AASM practice parameters for } \\
\text { treating CSA syndromes in adults }{ }^{6}\end{array}$ \\
\hline \multirow{2}{*}{ 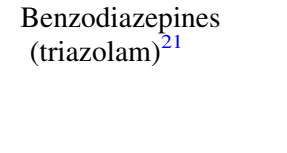 } & Possibly increases $\mathrm{PaCO}_{2}$ & May suppress central respiratory drive \\
\hline & $\begin{array}{l}\text { May decrease sleep fragmentation and sleep-onset central } \\
\text { apnea }\end{array}$ & $\begin{array}{l}\text { Triazolam can be considered as optional therapy for PCSA } \\
\text { if there are no underlying risk factors for respiratory } \\
\text { depression, according to AASM practice parameters }\end{array}$ \\
\hline Z-drugs (zolpidem) ${ }^{22}$ & Same as for benzodiazepines & Same as for benzodiazepines ${ }^{6}$ \\
\hline \multirow[t]{2}{*}{ Acetazolamide $^{23}$} & Carbonic anhydrase inhibitor & $\begin{array}{l}\text { Potential for serious adverse effects (e.g., sedation, } \\
\text { tinnitus, paresthesias, metabolic acidosis, and electrolyte } \\
\text { abnormalities) }\end{array}$ \\
\hline & & $\begin{array}{l}\text { Recommended as optional therapy for PCSA in the AASM } \\
\text { practice parameters }{ }^{6}\end{array}$ \\
\hline \multicolumn{3}{|l|}{$\begin{array}{l}\text { Positive airway } \\
\text { pressure devices }\end{array}$} \\
\hline \multirow[t]{2}{*}{$\mathrm{CPAP}^{24}$} & Unknown & May have no effect on CSA or may worsen CSA \\
\hline & & $\begin{array}{l}\text { Recommended as optional therapy for PCSA in the AASM } \\
\text { practice parameters }\end{array}$ \\
\hline \multirow[t]{2}{*}{$\begin{array}{l}\text { Bilevel PAP in the } \\
\text { spontaneous } \\
\text { mode }^{24,25}\end{array}$} & Unknown & $\begin{array}{l}\text { Can worsen CSA by decreasing } \mathrm{PaCO}_{2} \text {, particularly with } \\
\text { increasing pressure support (difference between } \\
\text { expiratory and inspiratory pressures) }\end{array}$ \\
\hline & & $\begin{array}{l}\text { No recommendation is given for this therapy in the AASM } \\
\text { practice parameters } 6\end{array}$ \\
\hline \multirow{3}{*}{$\begin{array}{l}\text { Bilevel PAP in the } \\
\text { spontaneous-timed } \\
\text { mode }^{25}\end{array}$} & Unknown & Recommended as optional therapy for PCSA in the AASM \\
\hline & $\begin{array}{l}\text { A breath can be initiated by the device when the patient's } \\
\text { respiratory rate is less than the set backup rate }\end{array}$ & practice parameters ${ }^{\circ}$ \\
\hline & $\begin{array}{l}\text { May be effective in some patients where CPAP or bilevel } \\
\text { PAP in the spontaneous mode is not effective in } \\
\text { eliminating CSA }\end{array}$ & \\
\hline \multirow{2}{*}{$\begin{array}{l}\text { Automatic or } \\
\text { adaptive } \\
\text { servoventilator } \\
\text { therapy }{ }^{5-7,20}\end{array}$} & $\begin{array}{l}\text { Dynamic breath-by-breath adjustment of pressure support } \\
\text { and backup rate that can eliminate CSA and normalize } \\
\text { breathing patterns }\end{array}$ & $\begin{array}{l}\text { Recommended as optional therapy for CSA in the AASM } \\
\text { practice parameters }{ }^{6}\end{array}$ \\
\hline & $\begin{array}{l}\text { Generally, more effective in reducing central sleep- } \\
\text { disordered breathing events than other PAP modalities } \\
\text { listed above }\end{array}$ & \\
\hline \multicolumn{3}{|l|}{ Inhaled gases } \\
\hline \multirow[t]{2}{*}{$\begin{array}{l}\text { Supplemental } \\
\text { oxygen }^{7,20}\end{array}$} & Can alleviate hypoxemia associated with CSA & $\begin{array}{l}\text { Theoretically, can prolong apnea by decreasing central } \\
\text { drive to breathe }\end{array}$ \\
\hline & & $\begin{array}{l}\text { There is no recommendation for oxygen therapy for PCSA } \\
\text { in the AASM practice parameters }\end{array}$ \\
\hline \multirow{2}{*}{$\begin{array}{l}\text { Supplemental carbon } \\
\text { dioxide }^{7,20,24,26}\end{array}$} & \multirow{2}{*}{$\begin{array}{l}\text { Can increase central drive to breathe by increasing the } \\
\mathrm{PaCO}_{2} \text { level }\end{array}$} & Limited clinical applicability \\
\hline & & $\begin{array}{l}\text { There is no recommendation for carbon dioxide for the } \\
\text { treatment of CSA in the AASM practice parameters }\end{array}$ \\
\hline
\end{tabular}

AASM = American Academy of Sleep Medicine; CPAP $=$ continuous positive airway pressure CSA $=$ central sleep apnea; $\mathrm{PAP}=$ positive airway pressure; PCSA = primary central sleep apnea; Z-drugs = nonbenzodiazepine benzodiazepine receptor agonist

doses of opioids were associated with worsening central apnea indices. ${ }^{11}$ The perioperative administration of opioid analgesics and other sedating medications in patients with PCSA may have unpredictable results on respiratory drive. Patients in our series, however, did not have any serious adverse events related to those medications. Nevertheless, two-thirds of the patients administered postoperative opioids and the patient administered zolpidem were continuously monitored for oxygen desaturation, and this added layer of safety may have contributed to the lack of 
adverse events. Until further evidence emerges, when postoperative PCSA patients require parenteral opioid analgesics, it may be prudent to observe them closely for signs of respiratory depression.

Similarly, little has been published on optimal PAP therapies for patients with PCSA ${ }^{5,6}$ (Table 3). Continuous PAP is generally tried first. ${ }^{5,6}$ Spontaneous-mode bi-level PAP devices can worsen nocturnal hyperventilation and paradoxically worsen PCSA. ${ }^{24,25}$ The ASV devices are sophisticated, new-generation devices that provide expiratory PAP but vary inspiratory PAP according to patient effort. ${ }^{28}$ Although their use has not been systematically assessed in patients with PCSA, they have shown superior efficacy for controlling disordered respiratory events and may confer better symptom management for other CSA syndromes. ${ }^{5}$ All patients in our series who used PAP devices had these newergeneration modalities. Although appropriate postoperative management has never been assessed in this patient population, we suggest that patients use their prescribed ASV device after surgery. Indeed, the one patient who had postoperative sedation and hypoxemia responded favorably to application of his home ASV device.

This study has all the inherent limitations of a retrospective review. Foremost, the data contained within the medical records may not accurately reflect patient acuity or provide a complete account of outcomes. Nevertheless, our practice uses a unique, robust protocol that continually monitors patients for signs of respiratory depression (e.g., apnea, bradypnea) during postanesthesia recovery in the PACU and uses those data to assess the postoperative course from retrospective records. ${ }^{17,29}$ Our data do not allow for detailed assessment of breathing parameters in sleep (e.g., during polysomnography). Patients using treatment modalities other than ASV were not evaluated in this study. Finally, our case series is small; therefore, our findings and observations have limited generalizability to all patients with PCSA.

In conclusion, our patients with PCSA who used home ASV and underwent procedures that required anesthesia generally tolerated the perioperative course well, and except for one patient, they did not have clinically notable worsening of their respiratory status or other complications directly related to PCSA. Nevertheless, these numbers are insufficient to establish the safety of anesthesia in this population, and we recommend that patients requiring general anesthesia or sedation and/or opioid analgesics undergo close postoperative monitoring.

Conflicts of interest Meghna P. Mansukhani is the principal investigator for a study funded by ResMed Foundation to evaluate the effects of adaptive servoventilation therapy for central sleep apnea syndromes on health care utilization; a subset of this cohort was assessed in the current study. Meghna P. Mansukhani received a benefactor-sponsored career development award at Mayo Clinic in Rochester, Minnesota, that is unrelated to the current study.

Toby N. Weingarten is a consultant to Medtronic, serving as chairman of the Clinical Endpoint Committee for the Prodigy Trial; he has received research support (study equipment) from Respiratory Motion, Inc., and unrestricted investigator-initiated grants from Merck (active) and Baxter (completed).

Editorial responsibility This submission was handled by Dr. Hilary P. Grocott, Editor-in-Chief, Canadian Journal of Anesthesia.

Author contributions Alexandru Alexa and Atousa Deljou collected data, analyzed and interpreted data, and helped write the manuscript. Meghna P. Mansukhani was involved in research design, collected data, analyzed and interpreted data, and helped write the manuscript. Bhargavi Gal was involved in research design, analyzed and interpreted data, and helped write the manuscript. Juraj Sprung analyzed and interpreted data and helped write the manuscript. Toby $N$. Weingarten was involved in research design, collected data, analyzed and interpreted data, carried out statistical analysis, and wrote the manuscript.

Funding Financial support was provided by the Mayo Clinic Department of Anesthesiology and Perioperative Medicine.

\section{References}

1. American Academy of Sleep Medicine. International Classification of Sleep Disorders. 3rd ed. Darien, IL: AASM; 2014 .

2. Xie A, Rutherford R, Rankin F, Wong B, Bradley TD. Hypocapnia and increased ventilatory responsiveness in patients with idiopathic central sleep apnea. Am J Respir Crit Care Med 1995; 152: 1950-5.

3. Xie A, Wong B, Phillipson EA, Slutsky AS, Bradley TD. Interaction of hyperventilation and arousal in the pathogenesis of idiopathic central sleep apnea. Am J Respir Crit Care Med 1994; 150: 489-95.

4. Meliana V, Chung F, Li CK, Singh M. Interpretation of sleep studies for patients with sleep-disordered breathing: what the anesthesiologist needs to know. Can J Anesth 2018; 65: 60-75.

5. Javaheri $S$, Brown $L K$. Positive airway pressure therapy for hyperventilatory central sleep apnea: idiopathic, heart failure, cerebrovascular disease, and high altitude. Sleep Med Clin 2017; 12: $565-72$

6. Aurora RN, Chowdhuri S, Ramar K, et al. The treatment of central sleep apnea syndromes in adults: practice parameters with an evidence-based literature review and meta-analyses. Sleep 2012; 35: 17-40.

7. Muza RT. Central sleep apnoea-a clinical review. J Thorac Dis 2015; 7: 930-7.

8. Kaw R, Chung F, Pasupuleti V, Mehta J, Gay PC, Hernandez AV. Meta-analysis of the association between obstructive sleep apnoea and postoperative outcome. Br J Anaesth 2012; 109 : 897-906.

9. Benumof JL. Mismanagement of obstructive sleep apnea may result in finding these patients dead in bed. Can J Anesth 2016; 63: 3-7.

10. Hillman DR, Chung F. Anaesthetic management of sleepdisordered breathing in adults. Respirology 2017; 22: 230-9.

11. Correa D, Farney RJ, Chung F, Prasad A, Lam D, Wong J. Chronic opioid use and central sleep apnea: a review of the 
prevalence, mechanisms, and perioperative considerations. Anesth Analg 2015; 120: 1273-85.

12. Ladd LA, Kam PC, Williams DB, Wright AW, Smith MT, Mather $L E$. Ventilatory responses of healthy subjects to intravenous combinations of morphine and oxycodone under imposed hypercapnic and hypoxaemic conditions. Br J Clin Pharmacol 2005; 59: 524-35.

13. Rocca WA, Yawn BP, St Sauver JL, Grossardt BR, Melton LJ 3rd. History of the Rochester Epidemiology Project: half a century of medical records linkage in a US population. Mayo Clin Proc 2012; 87: 1202-13.

14. St Sauver JL, Grossardt BR, Yawn BP, et al. Data resource profile: the Rochester Epidemiology Project (REP) medical records-linkage system. Int J Epidemiol 2012; 41: 1614-24.

15. Sessler CN, Gosnell MS, Grap MJ, et al. The Richmond Agitation-Sedation Scale: validity and reliability in adult intensive care unit patients. Am J Respir Crit Care Med 2002; 166: 1338-44.

16. Gali B, Whalen FX Jr, Gay PC, et al. Management plan to reduce risks in perioperative care of patients with presumed obstructive sleep apnea syndrome. J Clin Sleep Med 2007; 3: 582-8.

17. Gali B, Whalen FX, Schroeder DR, Gay PC, Plevak DJ. Identification of patients at risk for postoperative respiratory complications using a preoperative obstructive sleep apnea screening tool and postanesthesia care assessment. Anesthesiology 2009; 110: 869-77.

18. Javaheri $S$, Almoosa KF, Saleh K, Mendenhall CL. Hypocapnia is not a predictor of central sleep apnea in patients with cirrhosis. Am J Respir Crit Care Med 2005; 171: 908-11.

19. Weingarten TN, Jacob AK, Njathi CW, Wilson GA, Sprung J. Multimodal analgesic protocol and postanesthesia respiratory depression during phase I recovery after total joint arthroplasty. Reg Anesth Pain Med 2015; 40: 330-6.
20. Orr JE, Malhotra A, Sands SA. Pathogenesis of central and complex sleep apnoea. Respirology 2017; 22: 43-52.

21. Bonnet MH, Dexter JR, Arand DL. The effect of triazolam on arousal and respiration in central sleep apnea patients. Sleep 1990; 13: 31-41.

22. Quadri S, Drake C, Hudgel DW. Improvement of idiopathic central sleep apnea with zolpidem. J Clin Sleep Med 2009; 5: 122-9.

23. DeBacker WA, Verbraecken J, Willemen M, Wittesaele W, DeCock W, Van deHeyning P. Central apnea index decreases after prolonged treatment with acetazolamide. Am J Respir Crit Care Med 1995; 151: 87-91.

24. Hommura $F$, Nishimura $M$, Oguri $M$, et al. Continuous versus bilevel positive airway pressure in a patient with idiopathic central sleep apnea. Am J Respir Crit Care Med 1997; 155: 14825.

25. Johnson $K G$, Johnson DC. Bilevel positive airway pressure worsens central apneas during sleep. Chest 2005; 128: 2141-50.

26. Xie A, Rankin F, Rutherford R, Bradley TD. Effects of inhaled $\mathrm{CO} 2$ and added dead space on idiopathic central sleep apnea. J Appl Physiol 1985; 1997(82): 918-26.

27. White DP, Zwillich CW, Pickett CK, Douglas NJ, Findley LJ, Weil JV. Central sleep apnea. Improvement with acetazolamide therapy. Arch Intern Med 1982; 142: 1816-9.

28. Javaheri S, Brown LK, Randerath WJ. Positive airway pressure therapy with adaptive servoventilation: part 1: operational algorithms. Chest 2014; 146: 514-23.

29. Cavalcante AN, Sprung J, Schroeder DR, Weingarten TN. multimodal analgesic therapy with gabapentin and its association with postoperative respiratory depression. Anesth Analg 2017; 125: 141-6. 